\title{
Pharmacotherapy in Pediatric Obesity: Current Status and Future Prospects
}

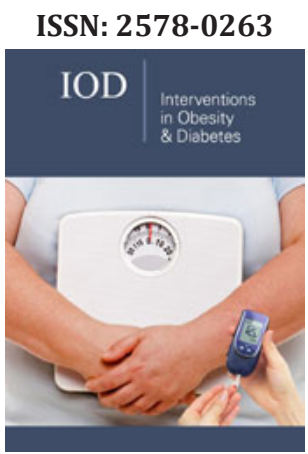

*Corresponding author: Karachaliou F, Unit of Pediatric Endocrinology and Diabetes, 3rd University Department of Pediatrics, Attikon University, Hospital, Greece

Submission: 監 April 24, 2020

Published: 俔June 03, 2020

Volume 4 - Issue 2

How to cite this article: Karachaliou F, Skarakis N, Simatos G, Boudouvi E, et al. Pharmacotherapy in Pediatric Obesity: Current Status and Future Prospects. Interventions Obes Diabetes 4(2). IOD.000582. 2020. DOI: 10.31031/IOD.2020.04.000582

Copyright@ Karachaliou F. This article is distributed under the terms of the Creative Commons Attribution 4.0 International License, which permits unrestricted use and redistribution provided that the original author and source are credited.

\author{
Karachaliou F*, Skarakis N, Simatos G, Boudouvi E, Spyropoulou T and \\ Papaevangelou V
}

Unit of Pediatric Endocrinology and Diabetes, 3rd University Department of Pediatrics, Attikon University, Hospital, Greece

\begin{abstract}
As obesity is principally a biologically mediated disease, biologically based interventions are often needed to counter the compensatory biological adaptations designed to maintain body weight at high levels. Pharmacotherapy can serve as an adjunctive treatment to lifestyle modification in some children and adolescents with obesity, especially those with severe forms of the disease and/or comorbidities. Despite the increasing number of anti-obesity drugs recently approved for the treatment of obesity in adults, few medications have been evaluated in terms of safety and efficacy in pediatric obesity. This mini review aims to provide some principles for the use of pharmacotherapy in pediatric obesity, summarizes results of some of the most important clinical trials on approved and "off-label" obesity medications and discusses some new options for the future of research on this field.
\end{abstract}

Keywords: Pediatric obesity; Pharmacotherapy; Anti-obesity agents; Weight loss

\section{Introduction}

Childhood obesity has globally an epidemic character with higher prevalence in developed countries, and higher rate of increase of prevalence in developing countries [1] Even more alarming is the increase in prevalence of severe obesity, defined as BMI $20 \%$ above the $95^{\text {th }} \mathrm{BMI}$ percentile or $\mathrm{BMI} \geq 35 \mathrm{~kg} / \mathrm{m}^{2}$ [2]. Severe obesity is associated with serious comorbidities including insulin resistance, and type 2 diabetes mellitus, hypertension, dyslipidemia, nonalcoholic fatty liver disease, obstructive sleep apnea, musculoskeletal problems, ovarian hyperandrogenism and psychosocial problems such as depression and anxiety [2,3]. Additionally many obese children, are already at the stage of prediabetes which is associated with development of micro- and macro- complications $[4,5]$ This stage has been estimated to progress to clinical diabetes with an annual rate of $5-10 \%$ in adults [6]. In a prospective study of obese adolescents with severe insulin resistance and impaired glucose tolerance (IGT), 24\% developed diabetes type 2 during a 21 months follow-up period, despite regular lifestyle modification intervention [7]. Unfortunately, treating obesity and especially the severe form, through lifestyle modification (behavioral treatment, healthy diet and enhancement of physical activity) has moderate effectiveness in younger children and poor in adolescents [8,9]. In a study including 648 children and adolescents with severe obesity, only $2 \%$ of adolescents succeeded in achieving and maintaining a clinically meaningful weight loss by lifestyle modification [8]. It appears that lifestyle modification can have considerable and durable effect only when applied intensively and uninterruptedly in highly motivated individuals. Studies have shown that intensive intervention (obligatory calories' restriction, multiple individual or/and group counseling sessions, daily exercise and multiple clinical visits) can lead to weight loss from 4.3 to $7 \mathrm{~kg}$ (4.5-6.5\% of body weight) during first year of application, while regular intervention has only poor results in the majority of children and adolescents [10-14]. Moreover, the majority of these lifestyle intervention studies are short term (6months-2years) and in most cases the benefit is eliminated from the rebound weight gain after the end of intervention [15]. 
It is important to acknowledge that obesity is a complicated and multifactorial disease necessitating a multifaceted approach. Energy balance is regulated from homeostatic and non-homeostatic mechanisms which can be dysregulated in the event of obesity [16]. Following weight loss (when energy stores are depleted) homeostatic mechanisms which are affected by neurotransmitters and gut hormones promote increased food consumption and decreased energy expenditure. Hence weight loss is followed by decrease in levels of leptin, insulin and triiothothyronin and increase in insulin sensitivity and plasma ghrelin levels [17]. These changes stimulate appetite, decrease sympathetic nervous system tone and energy consumption and enhance lipogenesis, thus facilitating weight regain. Non homeostatic mechanisms, the nature of which has not been entirely elucidated, including reward, cognition and emotional factors associated with food intake also participate in weight regain. It is believed that palatable food hyper-consumption has caused habituation to rewarding neural dopamine signaling. The weight loss is perceived as reward deficiency and leads to compensatory increase of food consumption [16]. Obviously these counter regulatory adaptations are observed in long term cases of obesity and are expected to persist for at least 12 months following weight loss and may even be permanent [18]. Therefore, it is reasonable to expect that the therapeutic approach must often combine lifestyle modification (focusing in external environment changing) with pharmacotherapy/bariatric surgery (focusing in internal biological environment changing) in order to be efficient and durable. This mini review focuses on pharmacotherapy as an adjuvant treatment to lifestyle modification, targeting homeostatic and non-homeostatic mechanisms of obesity in children and adolescents.

\section{Indications for Pharmacotherapy}

Despite the significant role of pharmacotherapy in obesity management and the increasing number of anti-obesity drugs approved for adults, only a few drugs have been assessed and fewer approved in children and adolescents with obesity. There is no concensus on the use of anti-obesity drugs in pediatric obesity regarding the appropriate age of treatment initiation and the necessity of treatment in obesity not associated with comorbidities. The criteria for adult obesity pharmacotherapy include: a) $\mathrm{BMI}>27 \mathrm{~kg} / \mathrm{m}^{2}$ with at least one obesity-related co-morbidity such as diabetes, sleep apnea, hypertension or hyperlipidemia or b) $\mathrm{BMI}>30 \mathrm{~kg} / \mathrm{m}^{2}$ with or without comorbidity. Based on these established criteria, modified indications have been proposed for children and adolescents : a) class 1 obesity ( $\mathrm{BMI} \geq 95^{\text {th }}$ percentile for age and sex or BMI $>30 \mathrm{~kg} / \mathrm{m}^{2}$ whichever is lower;) in the presence of at least one obesity-related co-morbidity or b) Class II $\left(\mathrm{BMI} \geq 120 \%\right.$ of $95^{\text {th }}$ percentile for age and sex or $\mathrm{BMI}>35 \mathrm{~kg} / \mathrm{m}^{2}$ whichever is lower) and Class III obesity (BMI $\geq 140 \% 95^{\text {th }}$ percentile for age and sex or BMI $>40 \mathrm{~kg} / \mathrm{m}^{2}$ whichever is lower) irrespective of the presence of co-morbidities [19]. Clinically meaningful weight loss has been defined as BMI z-score reduction between 0.20-0.25 s.d. over 6-12 months which is equivalent to a $5 \%$ change in BMI which has been associated with improvements in cardiovascular and metabolic risk factors in adults [20]. Regarding the duration of treatment, it is recommended that medication should be continued if a $>5 \%$ BMI reduction from baseline is maintained at 12 weeks or if arrest or slowing of weight gain is considered to be a reasonable clinical outcome [19]. Results and implications of the relatively small number of pediatric clinical trials of approved and off-label obesity drugs are discussed below.

\section{Medication Available for Pediatric Obesity-FDA Approved}

Orlistat is the only FDA approved medication for obesity $\geq 12$ years of age. It inhibits gastric and pancreatic lipase, thus reducing hydrolysis of food triglycerides to FFA. In the proposed dose of $120 \mathrm{mg}$ trice a day with meals, decreases fat absorption from food by $30 \%$. In a recent meta-analysis [20] including 779 adolescents 12-18years old, with mean BMI $37.4 \mathrm{~kg} / \mathrm{m}^{2}$, there was a slightly higher improvement in BMI in the group with orlistat: -0.94 [95\% CI, -1.58 to -0.30 ] vs placebo group : -0.50 (95\% CI, -7.62 to 6.62 ), with absolute weight change varying between +0.5 to $-5.5 \mathrm{~kg}$ in the orlistat group. In a randomized-controlled study assessing the effect of orlistat combined with lifestyle modification for 1 year on 352 adolescents resulted in a significant $-2.61 \mathrm{~kg}$ placebosubtracted weight loss $(\mathrm{p}<0.001)$ [10]. In general, orlistat treatment had a modest effect on cardiometabolic risk factors in contrast to data from adults where orlistat resulted in significant improvement of serum lipid profile and decrease od diabetes type 2 incidence $[21,22]$. The most common side effects were abdominal pain, flatus with discharge fatty/oily stool, increased defecation, and fecal incontinence. In conclusion orlistat produces small weight loss with no significant cardiometabolic benefit. The limited efficacy and low tolerability of the drug limits its clinical usefulness.

Phentermine is FDA- approved for age $>16$ years for short-term treatment (12 weeks) It has also been used as off-label drug in obese children $<16$ years or as long-term monotherapy. Phentermine is an amphetamine analogue that has been used in USA from 1959 in combination with topiramate [phentermine/topiramate extendedrelease] for obesity in adults. It produces appetite reduction, acting directly in hypothalamic satiety centers through cathecholamine release [23]. In a small retrospective study, 25 adolescents [mean age $16.1 \pm 1.3$ years] who were treated with phentermine plus lifestyle modification were compared to 274 adolescents with only lifestyle modification. At 6 months, a reduction of $-4.1 \%$ BMI (95\% CI: -7.1, -1.0\%; $p=0.009$ ) with phentermine plus lifestyle modification therapy was reported compared to lifestyle therapy alone [24]. The most commonly reported side effects are increase in heart rate and blood pressure, nervousness/and or insomnia. Less frequently, dizziness, dry mouth, difficulty sleeping, irritability, nausea/vomiting, diarrhea and constipation have been reported. 
It must not be co- administeresd with MAO inhibitors because of hypertensive crisis risk.

\section{Non FDA-approved medication with evidence from off- label use in pediatric obesity}

Metformin is FDA-approved in USA and Europe for the treatment of type 2 diabetes in adults and children $>10$ years old. The mechanism of action includes the suppression of hepatic neoglucogenesis, reduction of intestinal glucose absorption and small improvement of insulin sensitivity [25]. The mechanisms of weight loss, although not entirely known, include mainly the activation of AMP- activated protein kinase, the inhibition of ghrelin secretion and inhibition of dipeptyl peptidase 4 (DPP-IV) via glucagon-like peptide-1 (GLP-1) mediated reduction in caloric intake $[26,27]$. Although it has not official approval for use in obesity, metformin has been extensively used in many studies in children and adolescents without diabetes type 2. Recent meta-analysis [20] including 616 individuals aged 6-19years from 8 randomizedcontrolled studies [28-35] compared the use of metformin for 6-12 months to placebo. It was concluded that metformin in a dose varying from 1-2gr/day produced a small statistically significant reduction of BMI -score by -0.1 (95\% CI, -0.17 to -0.03 ) and of BMI by -0.86 (95\% CI, -1.44 to -0.29 ) [20]. In 6 out of the 8 studies, inclusion criteria comprised hyperinsulinemia, insulin resistance, impaired glucose tolerance (IGT) [28,30-34]. In one of these studies, subjects with IGT or abnormal HbA1c were excluded [35]. On the whole, mean weight change varied from $-2.27 \mathrm{~kg}$ to $+2.27 \mathrm{~kg}$ with metformin and from $-0.91 \mathrm{~kg}$ to $+5 \mathrm{~kg}$ with placebo. Metformin was well tolerable with minimal discontinuation rate $(<5 \%)$. No cases of lactic acidosis, hypoglycemia, rhabdomyolysis or hypertransaminasemia have been reported in children. The most commonly observed adverse effects were gastrointestinal symptoms (nausea, vomiting, and loose stools/diarrhea, bloating, flatus). Regarding cardiometabolic risk factors the comparison between metformin and placebo showed a modest superiority of metformin in reducing glucose, insulin and HOMA-IR and no benefit in change lipid profile or blood pressure [28,30,32,33,35].

Moreover, although meta-analysis showed only a small weight improvement of obese children, metformin has been proved notably effective in loss of weight gain related to anti- psychotic drugs in non-diabetic children [weight loss: $-4.1 \%, 95 \%$ CI 2.2-6.0] [36] and in adults with weight gain during mood/cognitive disorders leading to emotional eating, steroid use etc $[37,38]$. Metformin has also been extensively used in polycystic ovary syndrome in adolescents with or without obesity with good results in terms of weight loss and improvement of lipid profile and hirsuitism [3941]. It is also noteworthy that metformin administration in adults with prediabetes was reported to lead to significant reduction in incidence of type 2 diabetes [42]. Similar studies have not been performed in children and adolescents to date, but it is very likely that metformin could have an important role in prevention of type 2 diabetes in high risk pediatric population. Until to date, the management of obese children with prediabetes is individualized. The European Society of Endocrinology and the Pediatric Endocrine Society guidelines propose to avoid metformin use only for weight loss in obese children [43]. But they also suggest that the negative health impact may justify medication. Hence, in each case different aspects such as the metabolic profile, the comorbidities, the capacity of lifestyle modification etc should be considered in treatment decision. In conclusion, metformin is a safe drug with proven benefits and can be the first choice in certain cases. Further research is needed for the evaluation of its efficacy in the prevention of type 2 diabetes and long-term benefit in children and adolescents.

Topiramate although it is FDA approved for epilepsy $\geq 2$ years of age and migraine prophylaxis in $\geq 12$ years old, it has been shown to have beneficial effect on weight loss [44]. A possible mechanism of action is the inhibition of glutamate and carbonic anydrase receptors and the enhancement of $\gamma$-aminobutyrate (GABA) activity at calcium-sodium cell receptors [45]. Topiramate produces weight loss not only through reduction of food intake, but through increased energy consumption as well [44]. There are limited data from off-label topiramate use in children and adolescents. A small randomized controlled study evaluating topiramate (75mg daily) in 30 adolescents (12-17 years) with severe obesity, reported approximately a $2 \%$ BMI reduction at 6 months compared to placebo following short-term meal replacement intervention. The difference was not statistically significant (-1.9\%; $95 \%$ CI: $-5.2 \%$ to $+1.5 \%$; $P=0.291$ ) [46]. In another study assessing topiramate (75mg daily) for at least 3 months plus lifestyle intervention on 28 adolescents with severe obesity, a clinically meaningful BMI reduction was reported (-4.9\%, 95\% CI:-7.1, -2.8; $\mathrm{P}<0.001)$ [47]. There were not any serious adverse events in both studiew, except for paresthesia [46] in two patients. Paresthesia depression and anxiety have been also reported in studies on adults using phentermine/topiramat ER. There is strong recommendation for adolescents not using the medication during pregnancy, as the drug is a teratogen.

\section{GLP-1 Receptor Agonists [exenatide, liraglutide]}

Exenatide [GLP-1 receptor agonist] is FDA approved for diabetes type 2 in adults $>18$ years old. It is administered via subcutaneous injection. It stimulates GLP1 receptors in hypothalamus decreasing appetite and increasing satiety, with subsequent weight loss [48]. In a small, randomized, controlled study the administration of exenatide for 3 months in combination with lifestyle modification in 12 adolescents (9-16years) with severe obesity produced BMI reduction of $-1.7 \mathrm{~kg} / \mathrm{m}^{2}, 95 \% \mathrm{CI}-3.0$ to $-0.4, \mathrm{p}=0.01$ ) , weight loss : $-3.9 \mathrm{~kg}, 95 \% \mathrm{CI}-7.11$ to $-0.69, \mathrm{p}=0.02]$ and decrease of insulin levels :-7.5 mU/1, 95\% CI -13.71 to $-1.37, \mathrm{p}=0.02$ [49]. In another randomized controlled trial on 26 adolescents (12-19years) with severe obesity, exanetide produced a greater compared to controls 
reduction of $\%$ BMI of $-2.70 \%$ (95\% CI, $-5.02 \%$ to $-0.37 \%, \mathrm{p}=0.03$ ) and of weight 0 - $-3.26 \mathrm{~kg}$, (95\% CI $-5.87 \varepsilon \dot{\varepsilon} \omega \varsigma-0.66 \mathrm{~kg}, \mathrm{p}=0.02)$ (total weight reduction 4\%) [50]. The medication was well tolerated and the most common side effects were nausea, vomiting, abdominal pain and diarrhea.

Liraglutide another GLP1 receptor agonist is approved for diabetes type 2 in adults (1.2-1.8mg), for obesity $>18$ years ( $3 \mathrm{mg}$ ) and recently (2019) approved for diabetes type 2 in children $>10$ years.It was evaluated in a randomized, placebo-controlled, doubleblind study in 21 adolescents (12-17years), BMI $\geq 30 \mathrm{~kg} / \mathrm{m}^{2}$ to $\leq 45 \mathrm{~kg} / \mathrm{m}^{2}$ [51]. Adolescents were randomized to receive either liraglutide for 5 weeks $(0.6 \mathrm{mg} /$ week with weekly dose increase to a maximum of $3.0 \mathrm{mg}$ ) or placebo there was a greater decrease in both BMI and weight in those receiving liraglutide compared to controls, however the difference did not reach statistical significance. Similar randomized double blind study was performed in 24 children (7-11years), out of whom 14 received liraglutide $0.3 \mathrm{mg}$ daily with weekly increase to $3 \mathrm{mg}$ ) and 6 received placebo for 7-13 weeks [52]. A significant reduction in BMI z-score was observed $(-0.28 ; p=0.0062)$. The medication was safe and well-tolerated. The most common side effects were nausea, vomiting, abdominal pain and hypoglycemia. Moreover, there are indications that GLP1 agonists may be useful for weight regulation in patients with syndromic (Prader Willi) or hypothalamic (after tumor, trauma) obesity [53]. In conclusion GLP1 agonists are usually considered as alternative therapy in obese adolescents with type 2 diabetes when metformin and lifestyle modification fail. Lisdexamfetamine (LDX) FDA-approved for attention deficit hyperactivity disorder (ADHD) in children $\geq 6$ years and adults, and binge-eating disorder in adults. Mechanism of action is the increase of dopaminergic tone. In a controlled study in children (6-12yeras old) where LDX was administered for ADHD, weight reduction of $1.13 \mathrm{~kg}$ after 4 weeks was observed at a dose of 70mg [54] and in adolescents (13-17 years) of $2.2 \mathrm{~kg}$ for the same interval and dose [55]. In a more recent retrospective study of 25 patients (12-19years) who received LDX with diagnosis of binge-eating in the context of ADHD, the medication was well tolerated and resulted in improvement of binge-eating symptoms, although not significant improvement in BMI [55]. Since LDX is approved for ADHD in children $\geq 6$ years, it could potentially be a useful choice for children with ADHD and binge-eating. However there are concerns for the safety of drug as the long term use of amphetamines in pediatric populations are implicated in slowing in growth rate and cardiac arrhythmias. LDX should be avoided in cases of cardiac abnormalities.

\section{FDA-approved obesity medications with no evidence in pediatric obesity}

Lorcaserin is approved for obesity in adults in USA. It reduces food intake through selective activation of serotonin $2 \mathrm{c}$ receptors (5HT2C) in anorexiogenic neurons of propiomelanocortin (POMC) of hypothalamus. Studies in adults with obesity demonstrate a $3 \%$ placebo subtracted weight loss [56]. The most commonly reported side effects are headache, dizziness, fatigue, nausea, dry mouth and constipation. Ti must mot be coadministers with serotonergic medications. Naltrexone SR/bupropion SR (NB). Recently approved for obesity in adults in USA and Europe. It acts on hypothalamus by competitive binding of opioid receptors (naltrexone opioid antagonist) and selective inhibition of dopamine and noradrenaline reuptake (bupropion-antidepressant). The dose is 2 tb $8 / 90 \mathrm{mg}$ twice a day and the most common side effects include nausea, constipation, and dizziness. In adults the produce weight loss $4.8 \%$ greater than placebo. There are limited data from isolated use of each of the two components in children for other than obesity indications. Monotherapy with bupropion was applied in adolescents (12-17 years) for depression-without official approval even for this indication-and weight loss was observed as side effect in the majority of patients [57]. There is however great concern as for other antidepressants- for increased risk of suicide in children and adolescents [58]. Monotherapy with naltrexone has been applied in adolescents [ $>13$ years] opioid users [59] and in children with PWS for appetite control [60], but its long term safety in pediatric population has not yet been confirmed. There is one literature report of NB use from a girl with PWS who showed small $\mathrm{BMI}$ reduction and binge-eating improvement [61].

\section{Non FDA approved medication for pediatric obesity in the future}

Setmelanotide is a candidate for possible future approval for the treatment of monogenic obesity. Mechanism of action: melanocortin-4-receptor (MC4R) agonist. It is currently under evaluation for the management of genetic disorders which lead to obesity : POMC deficiency obesity, LepR deficiency obesity, PraderWilli syndrome, Bardet-Biedl syndrome, Alström syndrome, POMC heterozygous deficiency obesity, and POMC epigenetic disorders, In an open-label study setmelanotide was administered in two patients with POMC deficiency and produced substantial weight loss [62]. Adverse effects such as dry mouth, darkening of nevi and injection sites' induration have been reported. There are great expectations for its use in rare genetic forms of obesity which should be considered for children with hyperphagia and severe gradually aggravating obesity at a young age [ $<5$ years] [63].

\section{Conclusion}

Pharmacotherapy may often constitute a useful additional tool to intensive lifestyle modification for the treatment of pediatric obesity for some patients, especially those with severe forms. As energy balance is complicated with mechanisms directing against weight loss, pharmacotherapy often becomes a reasonable choice to target the underlying biology. The need for the development of well designed pediatric obesity trials is stressed to evaluate the long term safety and efficacy of obesity medication in pediatric populations. Furthermore the optimal time for starting, discontinuing, or intensifying treatment remains to be defined. 
Moreover, the future of research in the field of pharmacotherapy targets personalized treatment by pairing patients with the best therapeutic option with the lowest risk of side effects. The great heterogeneity in both the etiology of obesity and the responsiveness to therapy indicate that personalized strategies will be more effective than broadly applied treatment schemes.

\section{Acknowledgement}

Dr Skarakis, Dr Spyropoulou, Dr Boudouvi contributed in literature review. Dr G Simatos contributed in literature review and editing.

\section{References}

1. WHO: Facts and figures in childhood obesity.

2. Kelly AS, Barlow SE, Rao G, Inge TH, Hayman LL, et al. (2013) Severe obesity in children and adolescents: identification, associated health risks, and treatment approaches: A scientific statement from the American Heart Association. Circulation 128(15): 1689-1712.

3. Skinner AC, Perrin EM, Moss LA, Skelton JA (2015) Cardio metabolic risks and severity of obesity in children and young adults. N Engl J Med 373(14): 1307-1317.

4. Diabetes Prevention Program Research Group (2007) The prevalence of retinopathy in impaired glucose tolerance and recent-onset diabetes in the diabetes prevention program. Diabet Med 24(2): 137-144.

5. Ziegler D, Rathmann W, Dickhaus T, Meisinger C, Mielck A, et al. (2008) Prevalence of polyneuropathy in prediabetes and diabetes is associated with abdominal obesity and macroangiopathy: The MONICA/KORA Augsburg Surveys $\mathrm{S}_{2}$ and $\mathrm{S}_{3}$. Diabetes Care 31(3): 464-469.

6. Gerstein HC, Santaguida P, Raina P, Morrison KM, Balion C, et al. (2007) Annual incidence and relative risk of diabetes in people with various categories of dysglycemia: A systematic overview and meta-analysis of prospective studies. Diabetes Res Clin Pract 78(3): 305-312.

7. Weiss R, Taksali SE, Tamborlane WV, Burgert TS, Savoye M, et al. (2005) Predictors of changes in glucose tolerance status in obese youth. Diabetes Care 28(4): 902-909.

8. Danielsson P, Kowalski J, Ekblom O, Marcus C (2012) Response of severely obese children and adolescents to behavioral treatment. Arch Pediatr Adolesc Med 166(12): 1103-1108.

9. Knop C, Singer V, Uysal Y, Schaefer A, Wolters B, et al. (2015) Extremely obese children respond better than extremely obese adolescents to lifestyle interventions. Pediatr Obes 10(1): 7-14.

10. Godoy Matos A, Carraro L, Vieira A, Oliveira J, Guedes EP, et al. (2005) Treatment of obese adolescents with sibutramine: A randomized, double-blindcontrolled study. J Clin Endocrinol Metab 90(3): 14601465.

11. Poston WS, Reeves RS, Haddock CK, Stormer S, Balasubrmanyam A, et al. (2003) Weight loss in obese Mexican Americans treated for1-year with orlistat and lifestyle modification. Int J Obes Relat Metab Disord 27(12): 1486-1493

12. Berkowitz RI, Wadden TA, TershakovecAM, Cronquist JL (2003) Behavior therapy and sibutramine for the treatment of adolescent obesity: A randomized controlled trial. JAMA 289(14): 1805-1812.

13. Nemet D, Barkam S, Epstein Y, Friedland O, Kowen G, et al. (2005) Shortand long-term beneficial effects of a combined dietary-behavioralphysical activity intervention for the treatment of childhood obesity. Pediatrics 115(4): e443-e449.

14. Chanoine JP, Hampl S, Jensen C, Boldrin M, Hauptman J (2005) Effects of orlistat on weight and body composition in obese adolescents: A randomized controlled trial. JAMA 293(23): 2873-2883.
15. Ritchie LD, Crawford PB, Hoelscher DM, Sothern MS (2006) Position of the American Dietetes Association: individual-, family-,school- and community-based interventions for pediatric overweight. J Am Diet Assoc 106(6): 925-945.

16. Ochner CN, Tsai AG, Kushner RF, Wadden TA (2015) Treating obesity seriously: when recommendations for lifestyle change confront biological adaptations. Lancet Diabetes Endocrinol 3(4): 232-234.

17. Artz E, Haqq A, Freemark M (2005) Hormonal and metabolic consequences of childhood obesity. Endocrinol Metab Clin North Am 34(3): 643-658.

18. Sumithran P, Prendergast LA, Delbridge E, Purcell K, Shulkes A, et al. (2011) Long-term persistence of hormonal adaptations to weight loss. N Engl J Med 365(17): 1597-1604.

19. Srivastava G, Fox CK, Kelly AS, Jastreboff AM, Browne AF, et al. (2019) Clinical considerations regarding the use of obesity pharmacotherapy in adolescents with obesity. Obesity (Silver Spring) 27(2): 190-204.

20. O Connor EA, Evans CV, Burda BU, Walsh ES, Eder M, et al. (2017) Screening for obesity and intervention for weight management in children and adolescents: Evidence report and systematic review for the US preventive services task force. JAMA 317(23): 2427-2444.

21. Hutton B, Fergusson D (2004) Changes in body weight and serum lipid profile in obese patients treated with orlistat in addition to ahypocaloric diet: A systematic review of randomized clinical trials. Am J Clin Nutr 80(6): 1461-1468.

22. Torgerson JS, Hauptman J, Boldrin MN, Sjostrom L (2004) XENical in the prevention of diabetes in obese subjects (XENDOS) study: A randomized study of orlistat as an adjunct to lifestyle changes for the prevention of type 2 diabetes in obese patients. Diabetes Care 27(1): 155-161.

23. Fleming JW, McClendon KS, Riche DM (2013) New obesity agents: lorcaserin and phentermine/topiramate. Ann Pharmacother 47(7-8): 1007-1016

24. Ryder JR, Kaizer A, Rudser KD, Gross A, Kelly AS, et al. (2017) Effect of phentermine on weight reduction in a pediatric weight management clinic. Int J Obes (Lond) 41(1): 90-93.

25. Mehnert H (2001) Metformin, the rebirth of a biguanide: mechanism of action and place in the prevention and treatment of insulin resistance. Exp Clin Endocrinol Diabetes 109(Suppl 2): S259-S264.

26. Gagnon J, Sheppard E, Anini Y (2013) Metformin directly inhibits ghrelin secretion through AMP-activated protein kinase in rat primary gastric cells. Diabetes Obes Metab 15(3): 276-279.

27. Cuthbertson J, Patterson S, O Harte FP, Bell PM (2011) Addition of metformin to exogenous glucagon-like peptide- 1 results in increased serum glucagon-like peptide-1 concentrations and greater glucose lowering in type 2 diabetes mellitus. Metabolism 60(1): 52-56.

28. Wiegand S, I Allemand D, Hübel H, Krude H, Burmann M, et al. (2010) Metformin and placebo therapy both improve weight management and fasting insulin in obese insulin-resistant adolescents: A prospective, placebo-controlled, randomized study. Eur J Endocrinol 163(4): 585592.

29. Wilson DM, Abrams SH, Aye T, Phillip D K Lee, Carine Lenders, et al. (2010) Metformin extended release treatment of adolescent obesity: A 48-week randomized, double-blind, placebo-controlled trial with 48week follow-up. Arch Pediatr Adolesc Med 164(2): 116-123.

30. Yanovski JA, Krakoff J, Salaita CG, Jennifer R McDuffie, Kozloskyet M, et al. (2011) Effects of metformin on body weight and body composition in obese insulin-resistant children: A randomized clinical trial. Diabetes 60(2): 477-485.

31. Love Osborne K, Sheeder J, Zeitler P (2008) Addition of metformin to a lifestyle modification program in adolescents with insulin resistance. J Pediatr 152(6): 817-822. 
32. Kendall D, Vail A, Amin R, Barrett T, Dimitri P, et al. (2013) Metformin in obese children and adolescents: The MOCA trial. J Clin Endocrinol Metab 98(1): 322-329.

33. Srinivasan S, Ambler GR, Baur LA, Garnett SP, Tepsa M, et al. (2006) Randomized, controlled trial of metformin for obesity and insulin resistance in children and adolescents: improvement in body composition and fasting insulin. J Clin Endocrinol Metab 91(6): 2074 2080.

34. Freemark M, Bursey D (2001) The effects of metformin on body mass index and glucose tolerance in obese adolescents with fasting hyperinsulinemia and a family history of type 2 diabetes. Pediatrics 107(4): E55.

35. Clarson CL, Brown HK, De Jesus S, Jackman M, Mahmud FH, et al. (2014) Effects of a comprehensive, intensive lifestyle intervention combined with metformin extended release in obese adolescents. Int Sch Res Notices 2014: 659410.

36. Anagnostou E, Aman MG, Handen BL, Sanders KB, Shui A, et al (2016) Metformin for treatment of overweight induced by a typical antipsychotic medication in young people with autism spectrum disorder: A randomized clinical trial. JAMA Psychiatry 73(9): 928-937.

37. Bjorkhem Bergman L, Asplund AB, Lindh JD (2011) Metformin for weight reduction in non-diabetic patients on antipsychotic drugs: A systematic review and meta-analysis. J Psychopharmacol 25(3): 299-305

38. Cha DS, Vahtra M, Ahmed J, Kudlow PA, Mansur RB, et al. (2016) Repurposing of anti-diabetic agents for the treatment of cognitive impairment and mood disorders. Curr Mol Med 16(5): 465-473.

39. Hsia Y, Dawoud D, Sutcliffe AG, Viner RM, Kinra S, et al. (2012) Unlicensed use of metformin in children and adolescents in the UK. Br J Clin Pharmacol 73(1): 135-139.

40. Al Khalifah RA, Florez ID, Dennis B, Thabane L, Bassilious E (2016) Metformin or oral contraceptives for adolescents with polycystic ovarian syndrome: A meta-analysis. Pediatrics 137(5): e20154089.

41. Legro RS, Arslanian SA, Ehrmann DA, Hoeger KM, Murad MH, et al (2013) Diagnosis and treatment of polycystic ovary syndrome: An Endocrine Society clinical practice guideline. J Clin Endocrinol Metab 98(12): 4565-4592.

42. Knowler WC, Barrett Connor E, Fowler SE, Hamman RF, Lachin JM, et al. (2002) Reduction in the incidence of type 2 diabetes with lifestyle intervention or metformin. N Engl J Med 346(6): 393-403.

43. Styne DM, Arslanian SA, Connor EL Farooqi SI, Murad MH, Silverstein JH et al. (2017) Pediatric obesity-assessment, treatment, and prevention: An endocrine society clinical practice guideline. J Clin Endocrinol Metab 102(3): 709-757.

44. (2012) Product Information Topamax (topiramate). Titusville, USA.

45. Picard F, Deshaies Y, Lalonde J, Samson P, Richard D (2000) Topiramate reduces energy and fat gains in lean ( $\mathrm{Fa} /$ ?) and obese ( $\mathrm{Fa} / \mathrm{Fa})$ zucker rats. Obes Res 8(9): 656-663.

46. Fox CK, Kaizer AM, Rudser KD, Nathan BM, Gross AC, et al. (2016) Meal replacements followed by topiramate for the treatment of adolescent severe obesity: A pilot randomized controlled trial. Obesity (Silver Spring) 24(12): 2553-2561.

47. Fox CK, Marlatt KL, Rudser KD, Kelly AS (2015) Topiramate for weight reduction in adolescents with severe obesity. Clin Pediatr (Phila) 54(1): 19-24.
48. Grill HJ, Hayes MR (2009) The nucleus tractus solitarius: A portal forvisceral afferent signal processing, energy status assessment andintegration of their combined effects on food intake. Int J Obes 33(Suppl 1): S11-S15.

49. Kelly AS, Metzig AM, Rudser KD, Fitch AK, Fox CK, et al. (2012) Exenatide as a weight-loss therapy in extreme pediatric obesity: A randomized, controlled pilot study. Obesity (Silver Spring) 20(2): 364-370.

50. Kelly AS, Rudser KD, Nathan BM, Fox CK, Metzig AM, et al. (2013) The effect of glucagon-like peptide-1 receptor agonist therapy on body mass index in adolescents with severe obesity: A randomized, placebocontrolled, clinical trial. JAMA Pediatr 167(4): 355-360.

51. Danne T, Biester T, Kapitzke K, Jacobsen SH, Jacobsen LV, et al. (2017) Liraglutide in an adolescent population with obesity: A randomized, double-blind, placebo-controlled 5-week trial to assess safety, tolerability, and pharmacokinetics of liraglutide in adolescents aged 1217 years. J Pediatr 181: 146-153.

52. Mastrandrea LD, Witten L, Carlsson Petri KC, Hale PM, Hedman HK, et al. (2019) Liraglutide effects in a paediatric (7-11 y) population with obesity: A randomized, double-blind, placebo-controlled, short-term trial to assess safety, tolerability, pharmacokinetics, and pharmacodynamics Pediatr Obes14(5): e12495.

53. Salehi P, Hsu I, Azen CG, Mittelman SD, Geffner ME, et al. (2017) Effects of exenatide on weight and appetite in overweight adolescents and young adults with prader-willi syndrome. Pediatr Obes 12(3): 221-228.

54. (2017) Vyvanse (lisdexamfetamine dimesylate) Shire US, Lexington, MA, USA.

55. Guerdjikova AI, Blom TJ, Mori N, Matthews A, Cummings T, et al. (2019) Lisdexamfetamine in pediatric binge eating disorder: A retrospective chart review. Clin Neuropharmacol 42(6): 214-216.

56. Srivastava G, Apovian CM (2017) Current pharmacotherapy for obesity. Nat Rev Endocrinol 14(1): 12-24.

57. Glod CA, Lynch A, Flynn E, Berkowitz C, Baldessarini RJ (2003) Open trial of bupropion SR in adolescent major depression. J Child Adolesc Psychiatr Nurs 16(3): 123-130.

58. (2014) Contrave (naltrexone $\mathrm{HCl}$ and buproprion $\mathrm{HCl}$ extended release) Takeda Pharmaceuticals, Deerfield, IL, USA.

59. Hadland SE, Wharam JF, Schuster MA, Zhang F, Samet JH, et al. (2017) Trends in receipt of buprenorphine and naltrexone for opioid use disorder among adolescents and young adults, 2001-2014. JAMA Pediatr 171(8): 747-755

60. Benjamin E, Buot Smith T (1993) Naltrexone and fluoxetine in praderwilli syndrome. J Am Acad Child Adolesc Psychiatry 32(4): 870-873.

61. Puri MR, Sahl R, Ogden S, Malik S (2016) Prader-willi syndrome, management of impulsivity, and hyperphagia in an adolescent. J Child Adolesc Psychopharmacol 26(4): 403-404.

62. Kuhnen P, Clement K, Wiegand S, Blankenstein O, Gottesdiener K, et al. (2016) Proopiomelanocortin deficiency treated with a melanocortin-4 receptor agonist. N Engl J Med 375: 240-246.

63. Chen KY, Muniyappa R, Abel BS, Mullins KP, Staker P, et al. (2015) RM493, a melanocortin-4 receptor (MC4R) agonist, increases resting energy expenditure in obese individuals. J Clin Endocrinol Metab 100(4): 16391645.

For possible submissions Click below:

Submit Article 